\title{
PREPARATION OF MUCOADHESIVE GASTRORETENTIVE DRUG DELIVERY SYSTEM OF ALGINATE BEADS CONTAINING TURMERIC EXTRACT AND ANTI-GASTRIC ULCER ACTIVITY
}

\author{
HAKIM BANGUN ${ }^{1 *}$, FADLINA AULIA ${ }^{1}$, ANAYANTI ARIANTO ${ }^{1}$, MARLINE NAINGGOLAN ${ }^{2}$ \\ ${ }^{1}$ Department of Pharmaceutical Technology, Faculty of Pharmacy, Nanomedicine Centre of Innovation, University of Sumatera Utara, \\ Medan, Indonesia. ${ }^{2}$ Department of Pharmaceutical Biology, Faculty of Pharmacy, University of Sumatera Utara, Medan, Indonesia. \\ Email: hakimb17@yahoo.com
}

Received: 13 September 2018, Revised and Accepted: 13 November 2018

ABSTRACT

Objectives: The objectives of this study were to prepare the mucoadhesive mucoadhesive gastroretentive drug delivery system of alginate beads containing turmeric extract and to evaluate its anti-gastric effect.

Methods: Turmeric extract was made by macerating turmeric powder in ethanol $96 \%$ and evaporated using rotary evaporator at $50^{\circ} \mathrm{C}$ to obtained concentrated extract. Then, it was prepared alginate beads containing $5 \%$ turmeric extract by gelation method. The mucoadhesive properties of alginate beads containing turmeric extract were tested in vitro in male rats and the anti-gastric ulcer effect was tested on HCl-induced gastric ulcer in rats.

Results: The mean diameter of alginate beads obtained was $1.13 \pm 0.19 \mathrm{~mm}$. Bioadhesion test showed that alginate beads containing turmeric extract could be attached on gastric rats mucosa. Anti-gastric ulcer test showed that the healing of gastric lesions in rats was faster using alginate beads containing turmeric extract compared to untreated ones.

Conclusions: The results of this study suggest that mucoadhesive drug delivery systems of alginate beads containing turmeric extract are potentially developed as an anti-gastric ulcer.

Keywords: Turmeric extract, Alginate beads, Mucoadhesive, Gastroretentive, Anti-gastric ulcer.

(c) 2019 The Authors. Published by Innovare Academic Sciences Pvt Ltd. This is an open access article under the CC BY license (http://creativecommons. org/licenses/by/4. 0/) DOI: http://dx.doi.org/10.22159/ajpcr.2019.v12i1.29715

\section{INTRODUCTION}

Turmeric extract obtained from Curcuma domestica Val. contains curcumin which is the most effective component and has therapeutic effects such as anti-inflammatory, antibacterial, antifungal, anticancer, antioxidant, anti-human immunodeficiency virus, and antidiabetic. Other research has also demonstrated anti-inflammatory and antioxidant properties of curcumin [1,2]. Treatment of Helicobacter pylori with curcumin caused the relief of symptoms in peptic patients [3]. The anti-ulcer effect of curcumin might be due to its properties to decrease gastric acid secretion and enhance the mucosal defensive mechanism through suppression of inducible nitric oxide synthase (iNOS)-mediated inflammation [4]. Another interesting property of turmeric is the antibacterial activity, especially on enteric bacteria [5].

Ulcers are deep lesions penetrating through the gastrointestinal tract mucosa and muscularis mucosa. It is believed that peptic ulcers develop due to an imbalance between aggressive factors ( $H$. pylori, nonsteroidal anti-inflammatory drugs [NSAIDs], and gastric acid) and protective factors (mucin, bicarbonate, and prostaglandins) leading to an interruption in the mucosal integrity [6].

Curcumin has low solubility in water, slow absorption rates, and poor absorption in gastrointestinal tract which result in small concentration of curcumin entering the blood circulation and causing low efficacy. Low bioavailability of curcumin $(<1 \%)$ and degradation in the basic condition of human intestine will limit its clinical application $[7,8]$. Due to the instability of curcumin in basic condition of intestinal fluid, then it is necessary to prepare curcumin preparation in the gastroretentive drug delivery system to increase the bioavailability of curcumin. Oral drug delivery routes are the most convenient and most commonly used route of administration [9]. Gastroretentive systems can make drug remain in gastric region and prolong gastric residence time, thereby targeting site-specific drug release in the upper gastrointestinal tract for local or systemic effects. Several approaches of dosage formulations with gastroretentive system have been developed to achieve a controlled release of drug to stay longer in the stomach [10-16].

Mucoadhesive polymers have the ability to adhere to mucose substrate, and thus, the preparation can stay longer in delivery site, giving controlleddrug release and an increase of bioavailability. Alginate is a negatively-charged polysaccharide which is non-toxic, biocompatible, and biodegradable, included in anionic bioadhesive polymer, forming hydrogen bond with hydroxyl group in polysaccharide chain in mucus glycoprotein, and its chemical bond was non-covalent [17].

Lamivudine sodium alginate beads which were prepared by ionotropic gelation method showed prolonged drug release $(\sim 12 \mathrm{~h})$, and the release was controlled by diffusion from alginate beads that were slow and spread over an extended period of time depending on the drug-polymer ratio [18]. Floating drug delivery system of oil entrapped alginate beads formulation of curcumin showed that it has floating behavior and could release curcumin in a sustained manner for $8 \mathrm{~h}$ [19].

In this paper will be discussed the preparation, bioadhesion properties, and anti-gastric ulcer activity of mucoadhesive gastroretentive drug delivery system of alginate beads containing turmeric extract.

\section{MATERIALS AND METHODS}

Materials

Turmeric (C. domestica Val.) rhizome was obtained from Medan Central Market, Indonesia. The plant was authenticated by Herbarium Medanense University of Sumatera Utara, Indonesia. Ethanol 96\%, 
distilled water, and Tween 80 were obtained from Brataco, and sodium alginate $80-120 \mathrm{cP}$ was obtained from Wako Pure Chemical Industries, Ltd. Japan. Calcium chloride and hydrochloric acid were the products of Merck. All other chemicals were of analytical grade.

\section{Animals}

Healthy male Wistar rats weigh 150-200 g were housed in standard animal house and given standard pellet diets and tap water ad libitum. All rats were fasted from all medications at least 2 weeks before the test. All the rats were adhered to the standard operating procedures and approved by the Animal Research Ethics Committee of the Faculty of Mathematics and Natural Sciences, University of Sumatera Utara, beginning of the project work.

\section{Preparation of turmeric extract}

Turmeric powder was macerated with ethanol $96 \%$ for 8 days. Then, the macerate was evaporated with a rotary evaporator to obtain concentrated turmeric extract.

\section{Preparation of alginate beads}

Turmeric extract $\quad 5 \%$

Tween $80 \quad 5 \%$

Sodium alginate $\quad 1.5 \%$

Distilled water until $50 \mathrm{ml}$.

In brief, sodium alginate solution was prepared by adding sodium alginate $(1.5 \% \mathrm{w} / \mathrm{v})$ in distilled water. Turmeric extract was crushed with the addition of ethanol until dissolved, and it was mixed with Tween 80 , then added into the alginate solution, and stirred until the mixture became homogeneous. The mixture was dropped through a syringe with $21 \mathrm{G}$ size into $0.15 \mathrm{M}$ calcium chloride solution $(100 \mathrm{ml})$ with gentle agitation at room temperature with curing time of 4-5 min [20]. Then, the beads formed were separated from the solution by filtration and rinsed with distilled water. Finally, the beads containing turmeric acid were dried at room temperature and stored in a desiccator.

\section{Bioadhesion test}

Rats gastric mucosa was cleaned and soaked in sterile $0.9 \% \mathrm{NaCl}$ solution. Rats gastric mucosa was stuck to object glass with the mucosal part faces up. Tilted the object glass at $45^{\circ} .20$ alginate beads containing turmeric extract were attached to the gastric mucosa, and then it dropped with artificial gastric fluid and was placed in room temperature for $1 \mathrm{~min}$. Mucosa was flowed with artificial gastric fluid at a temperature of $37 \pm 0.5^{\circ} \mathrm{C}$ with a speed of $22 \mathrm{ml} / \mathrm{min}$. The number of beads left in mucosa was then counted after $5 \mathrm{~min}$ and $10 \mathrm{~min}[21,22]$.

Induction of gastric lesions by $1 \mathrm{~N} \mathrm{HCl}$ solution and healing of gastric lesions using alginate beads containing turmeric extract

Twenty-seven rats were fasted for $36 \mathrm{~h}$, and then, they were induced by $1 \mathrm{ml} 1 \mathrm{~N} \mathrm{HCl}$ solution to produce gastric lesions. After $1 \mathrm{~h}$ induced, three rats were sacrificed by ether, then the stomachs were opened and washed with $0.9 \% \mathrm{NaCl}$ solution, and the lesions were observed macroscopically and microscopically. Lesion index was determined by dividing the total area of lesions $\left(\mathrm{mm}^{2}\right)$ with the area of gastric mucosa $\left(\mathrm{mm}^{2}\right)$. The length and width of each lesion in $\mathrm{mm}$ were measured by calipers. The sum of the area of all lesions for each stomach was used in the calculation of the total lesions area [23]

The remaining rats (24 rats) were divided into two groups; each group consisted of 12 rats. Group I: Without treatment (given $2 \mathrm{ml}$ distilled water every day); Group II: Treatment group (given orally $100 \mathrm{mg} / \mathrm{kg}$ alginate beads containing turmeric extract every day). The rats were given standard pellet and tap water ad libitum. Then, three rats of each group were sacrificed on $2^{\text {nd }}, 4^{\text {th }}, 6^{\text {th }}$, and $8^{\text {th }}$ days. The gastric mucosa was observed macroscopically for the number of lesions, length, and width of lesions. For microscopic observation, the gastric mucosa was immersed in $10 \%$ formalin for histopathology processed with hematoxylin-eosin staining and observed using a microscope.

\section{RESULTS AND DISCUSSION}

\section{Preparation of alginate beads containing turmeric extract}

The use of turmeric extract in this experiment due to turmeric extract contains active ingredient curcumin. The addition of Tween 80 as a surfactant in the formulation was to increase the dissolution of curcumin which is practically insoluble in acidic condition. The alginate mixture containing turmeric extract and the Tween 80 was then dropped into $0.15 \mathrm{M} \mathrm{CaCl}_{2}$ solution using a syringe with curing time of 4-5 min to form spherical alginate gel beads that entrapped turmeric extract. Alginate is a linear natural polysaccharide consisting of $\beta$-D-mannuronic acid and $\alpha$-L-guluronic acid. Divalent cations, such as calcium ions, can bind to guluronate residues to form "egg box" structures and cause gelation [24,25]. The dried beads obtained were $1.30 \pm 0.05 \mathrm{~mm}$ in diameter and weigh $29.67 \pm 1.36 \mathrm{mg}$ as shown in Fig. 1 .

\section{Bioadhesion test}

Table 1 shows the bioadhesion test results of alginate beads containing $5 \%$ turmeric extract. Initially, the beads in mucosa were 20 beads, after 5 min flowed with $0.1 \mathrm{~N} \mathrm{HCl}$ solution, the average beads remained in rats mucosa were 17 beads (87\%), and after $10 \mathrm{~min}$, average beads remained in rats mucosa were $16(81 \%)$. These results indicate the mucoadhesive properties of alginate beads.

Mucoadhesive polymers are composed of polar functional groups such as the hydroxyl $(-\mathrm{OH})$, carboxyl $(-\mathrm{COOH})$, amide $(-\mathrm{NH} 2)$, and sulfate $(-\mathrm{SO} 4)$ groups which can interact with the mucin glycoprotein [26]. Alginate contains the $-\mathrm{OH}$ and $(-\mathrm{COOH})$ groups causing it to have mucoadhesive properties, so it can be used as a gastroretentive pharmaceutical excipient that attached to the gastric mucosa. Previous study was also reported the bioadhesive properties of alginate beads $[12,13]$.

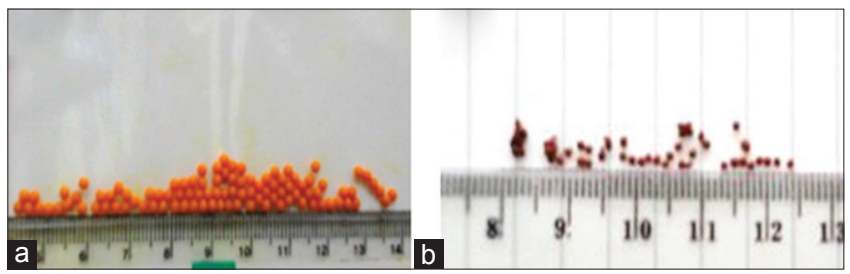

Fig. 1: Photograph of alginate beads containing turmeric extract. Before (a) and after (b) drying
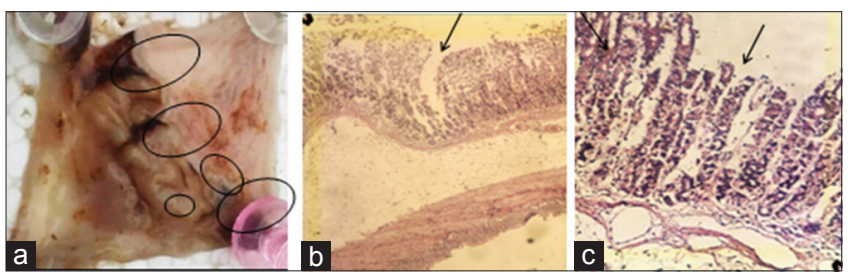

Fig. 2: Macroscopic (a) and microscopic (b and c) pictures of rat stomach after induction with $1 \mathrm{~N} \mathrm{HCl}$ solution. Circles show the gastric lesions. Magnification: $b: \times 10, c: \times 100$. Arrows show the erosion of gastric mucosa tissue

Table 1: Data of bioadhesion test of alginate beads containing turmeric extract

\begin{tabular}{llll}
\hline \multirow{2}{*}{ Experiment } & \multicolumn{3}{l}{ Number of beads left in mucosa } \\
\cline { 2 - 4 } & Initial & $\mathbf{5}$ $\mathbf{~ i n}$ & $\mathbf{1 0} \mathbf{~}$ in \\
\hline 1 & 20 & 15 & 15 \\
2 & 20 & 18 & 15 \\
3 & 20 & 19 & 19 \\
Mean & & 17 & 16 \\
Mean percentage & & 87 & 81 \\
\hline
\end{tabular}


Induction of gastric mucosa lesion using $1 \mathrm{~N} \mathrm{HCl}$ solution

Fig. 2 shows the control group of rats lesion after $1 \mathrm{~h}$ induced by $1 \mathrm{~N} \mathrm{HCl}$ solution. The erosion formed is shown by the circle image. The condition of these rats stomach (number of lesions and value of ulcer index) as shown in Table 2 is considered as initial condition of rats after induction with $1 \mathrm{~N} \mathrm{HCl}$ solution. Damage and erosion of epithelial cells that are deep enough (shown by circle image) on the surface of the gastric mucosa are due to direct contact with $\mathrm{HCl}$ solution. Local irritation leads to tissue damage and causes back diffusion of stomach acid to the mucosa [27]. The etiology of gastric ulcers is due to an imbalance between aggressive factor (H. pylori, NSAID, and gastric acid) and protective factors (mucin, bicarbonate, and prostaglandin), leading to the disruption of the mucosal integrity [6]. Peptic ulcer occurs when aggressive effects of acid-pepsin outweigh the protective effects of gastric mucosa [28].

Fig. 2 shows the macroscopic and microscopic pictures of rats gastric mucosa $1 \mathrm{~h}$ after induction with $1 \mathrm{~N} \mathrm{HCl}$ solution.

Treatment of gastric lesions with alginate beads containing turmeric extract

\section{Macroscopic observation of rats stomach}

The macroscopic observation of rats stomach was done by counting the number of gastric lesions and the area of lesion and then calculated the lesion index. The number of lesions in both the groups is shown in Table 2, while the average lesion index in both groups is shwon in Table 3. Fig. 3 shows the macroscopic pictures of rats mucosa that were not treated (upper) and that were treated with alginate beads containing turmeric extract during 8 days. The more days of treatment, the less of the number of lesions and the lower the lesion index value. Reduction of the number of lesions and lesion index value was faster in rats given alginate beads containing turmeric extract compared to rats that were not given beads. This means that alginate beads containing turmeric extract have anti-gastric ulcer activity.

After the administration of the beads, in the stomach in the presence of gastric fluid, curcumin is released from the beads. The anti-ulcer effect of curcumin is due to its properties to decrease the gastric acid secretion and increased the mucosal defense mechanisms through inflammatory suppression mediated by NO synthase enzyme [4]. Wound healing is a process involving growth factor of peptides where transforming growth factor (TGF)-beta is one of the most important. NO is also an important factor of healing, and its production is controlled by iNOS. Curcumin significantly accelerates wound healing due to an increased expression of TGF-beta 1 and TGF-beta tllrc and increased iNOS levels [29]. Other properties of curcumin are antibacterial activity, especially in enteric bacteria [5].

\section{Microscopic observation of rats stomachs}

Fig. 4 shows the microscopic pictures of a normal rat stomach, and it is a representative of a normal condition of rats gastric mucosa

Table 2: Average number of lesionsof each group $(n=3)$

\begin{tabular}{lll}
\hline Days & Without treatment & $\begin{array}{l}\text { Given alginate beads containing } \\
\text { turmeric extract }\end{array}$ \\
\hline 0 & $8.67 \pm 1.15$ & \\
2 & $8.00 \pm 1.00$ & $6.67 \pm 1.52$ \\
4 & $13.67 \pm 1.52$ & $3.67 \pm 1.52$ \\
6 & $3.33 \pm 3.51$ & $1.00 \pm 1.73$ \\
8 & $1.33 \pm 2.30$ & 0 \\
\hline
\end{tabular}

Table 3: Average lesion index of each group $(n=3)$

\begin{tabular}{lll}
\hline Days & Without treatment & $\begin{array}{l}\text { Given alginate beads containing } \\
\text { turmeric extract }\end{array}$ \\
\hline 0 & $0.0947 \pm 0.0378$ & \\
2 & $0.1078 \pm 0.0227$ & $0.0460 \pm 0.0380$ \\
4 & $0.0190 \pm 0.0084$ & $0.0174 \pm 0.0204$ \\
6 & $0.0984 \pm 0.1623$ & $0.0001 \pm 0.0001$ \\
8 & $0.0035 \pm 0.0061$ & 0 \\
\hline
\end{tabular}

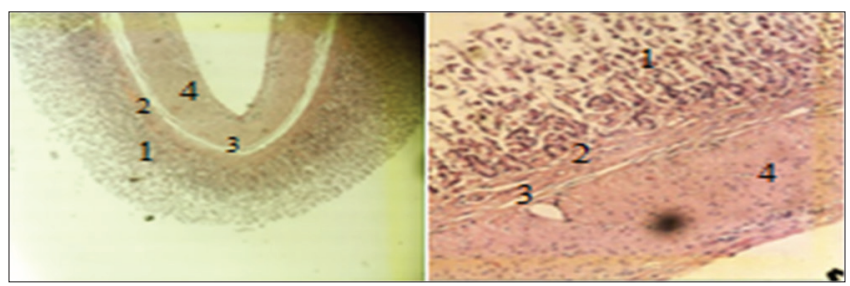

Fig. 4: Microscopic pictures of a normal rat stomach. Magnification left $(\times 40)$ and right $(\times 100)$. (1) Mucosal layer, (2) mucosal muscular layer, (3) submucosal layer, (4) tunic muscular layer

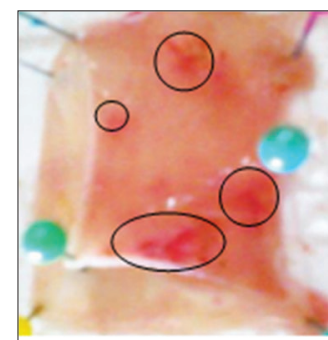

day 2

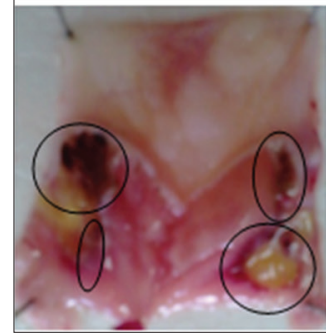

day 4

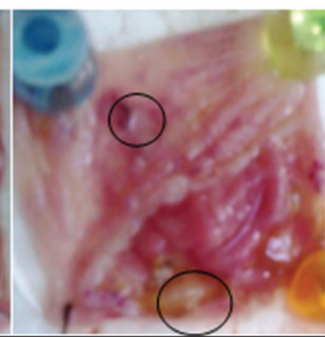

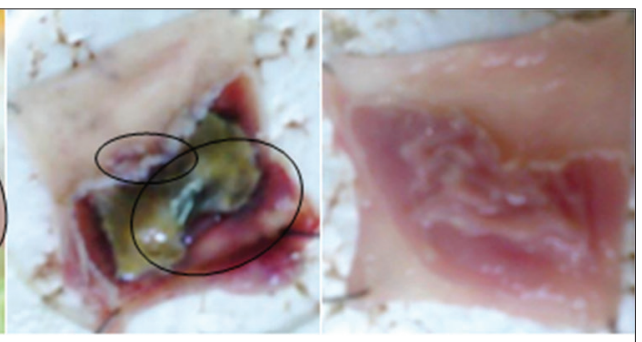

day 6

day 8
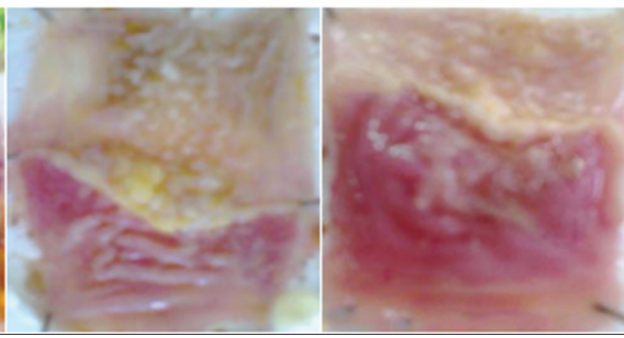

Fig. 3: Macroscopic pictures of representative of rats stomach during 8 days. Without treatment (upper) and with treatment with alginate beads containing turmeric extract (under) 


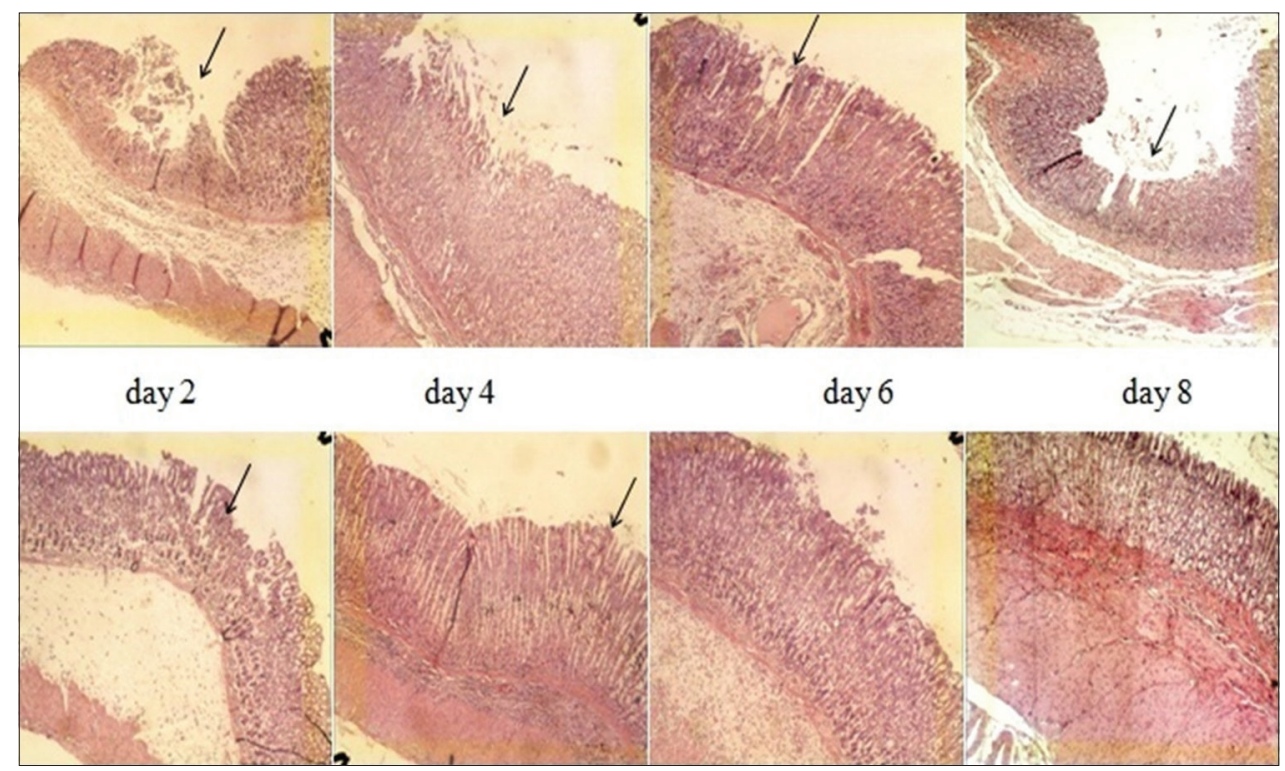

Fig. 5: Microscopic picture of representative rats stomachs. Without treatment (upper) and with treatment with alginate beads containing tumeric extract (under) $(\times 40)$. Arrows show the erosion of tissue

Table 4: Conditions of rats gastric mucosa after induction with $1 \mathrm{~N} \mathrm{HCl}$ solution during 8 days of treatment compared to rats without treatment. Each subgroup consisted of three rats

\begin{tabular}{|c|c|c|c|c|c|c|c|c|c|c|c|c|c|c|c|}
\hline \multirow[t]{2}{*}{ Group of rats } & \multicolumn{15}{|c|}{ Days } \\
\hline & $\mathbf{0}$ & & & 2 & & & 4 & & & 6 & & & 8 & & \\
\hline Treatment group & $\mathrm{x}$ & $\mathrm{x}$ & $\mathrm{x}$ & $x$ & $\mathrm{x}$ & $\mathrm{x}$ & $\mathrm{x}$ & o & o & o & o & o & 0 & o & o \\
\hline Without treatment group & $\mathrm{x}$ & $\mathrm{x}$ & $\mathrm{x}$ & $\mathrm{x}$ & $\mathrm{x}$ & $\mathrm{x}$ & $\mathrm{x}$ & $\mathrm{x}$ & o & $\mathrm{x}$ & $\mathrm{x}$ & 0 & $\mathrm{x}$ & o & o \\
\hline
\end{tabular}

Fig. 5 shows the comparison gastric lesions between group without treatment and group with treatment with alginate beads containing turmeric extract. Microscopic observation shows that, at day 2, there are still damage and erosion of gastric mucosa in both groups. At day 4, there are differences, in which the epithelial cells of a group without treatment show the erosion in all three rats tested, whereas in the group with treatment, the epithelial cells begin to approach normal condition. The microscopic observation at day 6 shows that the group without treatment still has erosion while group with treatment shows all in normal epithelial cells. Microscopic observation at day 8 shows that the group of without treatment there are still erosion of gastric mucosa, while group with treatment with alginate beads containing turmeric extract shows all in normal gastric mucosa.

Healing peptic ulcers require rearrangement of epithelial structures and the connective tissues, including the lining of the vessels and muscles. Several growth factors have been involved in this process, because of their ability to regulate important cell functions, such as cell proliferation, migration, differentiation, secretion, and extracellular matrix degradation, where everything are important during tissue healing [30].

Table 4 summarizes the condition of rats gastric mucosa after induction with $1 \mathrm{~N} \mathrm{HCl}$ solution during treatment with alginate beads containing turmeric extract for 8 days compared to rast without treatment. This evaluation was done based on the results of macroscopic and microscopic observations. At day 4, two of three treated rats group were healed. However, on non-treated group, only one of three of rats tested was healed. At day 6, all of three treated rats group was healed. However, on rats of non-treated group, only one rat was healed. Even, at day 8 , one rat was not recovery from three rats tested. Thus, it can be concluded that alginate beads containing turmeric extract have an anti-gastric ulcer effect. Therefore, in general, it can be concluded that alginate beads containing turmeric extract are effective as anti-gastric ulcer.

\section{CONCLUSIONS}

Mucoadhesive gastroretentive alginate beads containing turmeric extract are successfully prepared and showed that this product has a mucoadhesive properties and it heals the stomach lesions faster than that without treatment.

\section{ACKNOWLEDGMENT}

This work was supported by the University of Sumatera Utara grant 2018 through the scheme of TALENTA.

\section{AUTHORS' CONTRIBUTIONS}

Hakim Bangun planned and designed the study, Fadlina Aulia conducted the study, Anayanti Arianto supported the conduction of study, and Marline Nainggolan supported the preparation of turmeric extract preparation.

\section{CONFLICTS OF INTEREST}

The authors declare that they have no conflicts of interest.

\section{REFERENCES}

1. Rafatullah S, Tariq M, Al-Yahya MA, Mossa JS, Ageel AM. Evaluation of turmeric (Curcuma longa) for gastric and duodenal anti-ulcer activity in rats. J Ethnopharmacol 1990;29:25-34.

2. Mukerji B, Saidi SH, Singh GB. Species and gastric function: Part I. Effect of Curcuma longa on the gastric secretion in rabbits. J Sci Ind Res 1961;20:25-8.

3. Koosirirat C, Linpisam S, Changsom D, Chawansuntati K, Wipasa J. Investigation of the anti-inflammatory effect of Curcuma longa in Helicobacter pylori-infected patients. Int Immunopharm 2010;10:815-8.

4. Mahattanadul S, Nakamura T, Panichayupakaranant P, Phdoongsombut N, Tungsinmunkong K, Bouking P. Comparative antiulcer effect of bisdemethoxycurcumin and curcumin in a gastric ulcer model system. Phytomedicine 2009;16:342-51.

5. Farnsworth NR, Bunyapraphatsara T. Thai Medicinal Plants. $1^{\text {st }}$ ed. Bangkok: MPIC; 1992. p. 402.

6. Sunil K, Amandeep K, Robin S, Ramica S. Peptic ulcer: A review on etiology and pathogenesis. Int Res J Pharm 2012;3:34-5.

7. Anand P, Kunnumakkara AB, Newman RA, Aggarwal BB. 
Bioavailability of curcumin: Problems and promises. Mol Pharm 2002;4:807-18.

8. Jefferson W. The Healing Power of Tumeric. United States of America: Healthy Living Publications; 2015. p. 298-302.

9. Nayak AK, Maji R, Das B. Gastroretentive drug delivery system: A review. Asian J Pharm Clin Res 2010;3:2-10.

10. Dhiman S, Singh TG, Rehni AK, Sood S, Arora S. Gastroretentive: A controlled release drug delivery system. Asian J Pharm Clin Res 2011;4:5-13.

11. Shasank C, Prabha K, Sunil S, Kumar AV. Approaches to increase the gastric residence time: Floating drug delivery systems - A review. Asian J Pharm Clin Res 2013;6:1-9.

12. Arianto A, Bangun H, Harahap U, Ilyas S. The comparison of swelling, mucoadhesive, and release of ranitidine from spherical matrices of alginate, chitosan, alginate-chitosan, and calcium alginate-chitosan. J Pharm Tech Res 2014;6:2054-63.

13. Arianto A, Bangun H, Harahap U, Ilyas S. Effect of alginate chitosan ratio on the swelling, mucoadhesive, and release of ranitidine from spherical matrices of alginate-chitosan. Int J Pharm Tech Res 2015;8:653-65.

14. Arianto A, Bangun H, Yohana A, Silalahi J. Floating gastroretentive of amoxicillin using hard alginate capsules and its antibacterial activities. Asian J Pharm Clin Res 2017;10:413-9.

15. Adliani N, Bangun H, Karsono P. Preparation and evaluation of floating-mucoadhesive alginate beads as gastroretentive drug delivery system of antacids. Int J PharmTech Res 2016;9:212-22.

16. Siahaan DR, Bangun H, Sumaiyah I. In vitro and in vivo evaluation of floating gastroretentive drug delivery system of cimetidine using hard alginate capsules. Asian J Pharm Clin Res 2018;11:162-8.

17. Vetter A, Schnurch AB. Bioadhesive Delivery Systems. Biodrug Delivery Systems: Fundamentals, Applications and Clinical Development. Boca Raton: CRC Press; 2010. p. 220-1.

18. Reddy DR, Malleswari K, Prasad G, Prasanna D. Preparation and in vitro evaluation of lamivudine floating sodium alginate beads. Int $\mathrm{J}$
Pharm Clin Res 2012;4:81-8.

19. Petchsomrit A, Sermkaew N, Wiwattanapatapee R. Effect of alginate and surfactant on physical properties of oil entrapped alginate bead formulation of curcumin. Int J Med Health Biomed Bioeng Pharm Eng 2013;7:864-8

20. Bangun H. Physico-Pharmaceutical Studies on Drug Binding to and Drug Release from Alginate. Tokushima: Faculty of Pharmaceutical Sciences, The University of Tokushima; 1990. p. 44-6.

21. Lenaerts VM, Gurny R. Bioadhesive Drug Delivery Systems. Florida: CRC Press, Ic.; 1990. p. 46.

22. Gaserod O, Jolliffe G, Hampson FC, Dettmar PW, Skjak-Braek, G. The enhancement of the bioadhesive properties of calcium alginate gel beads by coating with chitosan. Int J Pharm 1998;175:237-46.

23. Arianto $H$, Bangun $H$. Healing effect of alginate liquid against $\mathrm{HCl}$-induced gastric mucosal lesions in rats. Int $\mathrm{J}$ PharmTech Res 2016;9:287-96.

24. Grant GT, Morris ER, Rees DA, Smith PJ, Thom D. Biological interactions between polysaccharides and divalent cations - Egg-box Model. Febs Lett 1973;32:195-8

25. Smidsrod O, Skjak-Brik G. Alginate as immobilization matrix for cells. Trend Biotechnol 1990;8:71-8.

26. Yu T, Andrews, GP, Jones, DS. Mucoadhesion and characterization of mucoadhesive properties. In: Mucosal Delivery of Biopharmaceuticals: Biology, Challenges and Strategies. New York: Springers; 2014. p. 35-43.

27. Sherwood L. Human Physiology: From Cells to System. Jakarta: EGC; 2001. p. 538-60.

28. Isselbacher H. Harrison's Principles of Internal Medicine. Jakarta: EGC; 2000. p. 1532-49.

29. Mani H, Sidho GS, Kumari R, Gaddipati JP, Seth P, Maheshwari RK. Curcumin differentially regulates TGF-beta1, Its receptors and nitric oxide synthase during impaired wound healing. Biofactors 2002;16:29-43.

30. Milano S, Calabro S. Role of growth factors and their receptors in gastric ulcer healing. Microsc Res Tech 2001;53:360-71. 